\title{
Omics: A Newer Technique in Herbal Drug Standardization and Quantification
}

\author{
Ravindra Pandey ${ }^{1 *}$, Raj Kumar Tiwari ${ }^{2}$, Shiv Shankar Shukla ${ }^{1}$ \\ 'Department of Pharmacognosy, Columbia Institute of Pharmacy, Raipur, C.G. INDIA. \\ 2Department of Pharmacology, Columbia Institute of Pharmacy, Raipur, C.G. INDIA.
}

\begin{abstract}
Herbal plants are found abundant in all parts of the world with various uses for its medicinal, pharmaceutical, and nutritional value as well as the ordinary spice in our culinary. Nature is a principal source of herbal medicines. The increasing use of herbal medicine around the globe requires new scientific approaches for their standardization. Evaluation of Physical and chemical parameters are the most common parameters for standardization. Now days, a number of method exists, but not satisfying everyone all over the globe. With the use of newer technique such as omics, (proteomics, metabonomics, transcriptomics etc.), we can easily have depth knowledge of pharmacodyanamics, pharmacokinetics and toxicological characterization of active constituent of an herbal plant. These techniques have made one standard approach for the standardization and modernization of herbal medicine. The modernization of herbal medicine is the need of hour to cater the global demand by means of patient compatibility. The omic technique can also play an important role for the conservation of knowledge of ancient
\end{abstract}

plant species. Moreover omic technique is an important tool for fingerprinting and quality control of herbal medicine. In this review, an emphasis has been made on different techniques of omics and their use in standardization and modernization of herbal plant.

Key words: Metabomics, Omics, Prteomics, Standardization, Transcriptomics.

Correspondence :

Dr. Ravindra Pandey,

Asso. Professor, Department of Pharmacognosy,

Columbia Institute of Pharmacy, Raipur, C.G., INDIA.

Phone no: 0982622932

Email: ravindra56@rediffmail.com, ravindraiop@gmail.com

DOI: 10.5530/jyp.2016.2.4

\section{INTRODUCTION}

Herbal medicines have a long history of use for the prevention and treatment of diseases. The use of medicinal plants with therapeutical purposes represents a secular tradition in different cultures. ${ }^{1}$ Their use was traced back to the first written testimonies of different book of Ayurveda. They have always been part of human culture. About $80 \%$ of world populations still rely on medicinal herbs for their primary health care, according to WHO. Not only in India but also in western nations the use of herbal medicine is increasing day by day. ${ }^{2}$ Standardization of herbal plant is a critical issue to ensure the quality of the research process for safety and efficacy of the research products, which are critical to scientists and regulators for ensuring the quality and interoperability of herbal products. ${ }^{3}$

The standardization parameter which is studied, provides knowledge about the various properties of the plant such chemical constituents, ash value, etc. but with the use of the omic science, we can study standardization to great extent regarding DNA properties and the other things related to DNA and RNA. This is most evident in the case of 'omics science, which is mainly done by diverse high-throughput technologies such as genomics, proteomics, and metabolomics. ${ }^{3}$ Scientific evidence to prove the rationale of using traditional formulations in health care is essential to develop and to preserve the cultural heritage. ${ }^{4}$

The term "omic" was derived from the Latin suffix "ome" meaning mass or many. With the beginning of information-rich techniques such as genomics, proteomics and transcriptomics as well as various profiling approaches, including metabolomics (a non-targeted analytical approach, usually concentrating on molecules of low molecular weight) and metabomics, it has recently become possible to examine simultaneous molecular effects of mixtures of chemical agents. ${ }^{5}$

The present article feud that standardization of omic science is socioeconomic. A critical preparation of the herbal medicine illustrates: (1)
A degree of flexibility is to be required for standardization at the level of scientific practice, (2) the way standards was created, (3) the process of standardization itself is important for establishing the legitimacy of an area of scientific research. The study of "Omics" involves a large number of assessments per endpoint to gain extensive, integrated knowledge and simultaneously show the different factors than each of that separately. ${ }^{6}$

\section{Development of use OMIC technique in herbal medicine}

With the advancement in omic technique, the use of omic science is originating nearly in all biomedical fields. Omic techniques provide simultaneous assessment of classes of molecule, which are the main experimental spree for such an approach. Potential for application of omic analytical technologies and bioinformatics studies involving herbal medicine have higher cost and the range of multidisciplinary expertise is required for their application which initially constrained their application. ${ }^{7}$ Omic technique is mainly used for identification of biomedical resources such as genomic technique in DNA sequencing and fingerprinting or DNA microarrays. All the research works mainly related to biological issue mostly addressing the corroboration and quality control of herbal products. With the increase in pharmacological studies, the newer trends are established for the use of omic technique in the field of herbal plant related to pharmacological experiment. Proteomic technique have been applied for the treatment of cardiovascular diseases, epilepsy cancer etc. with the herbal medicine. ${ }^{8}$

One of the most remarkable applications of proteomics in herbal medicine is the capability of this technique to identify different species. These applications would be very valuable tool for the quality control, toxicity studies, and standardization of herbal preparation. ${ }^{9}$ A number of DNA polymorphism based assay are developed for identification of herbal products. DNA is amplified by polymerase chain reaction (PCR). DNA chip with DNA sequences proved to be more powerful tool that could 
be also used for analyzing mixed herbal preparation. ${ }^{10}$ Microanalysis of gene expression allows rapid and detailed analysis of thousands of transcripts. Gene chip technology is one of the most powerful tools for elucidating the molecular mechanism and the network under laying the complex pharmacological function of herbal preparation. These techniques properly coupled with bioinformatics and statistical can be used for pharmacodyanamics, pharmacokinetics, and toxicological characterization of herbal drugs. ${ }^{11}$

The omics technologies collect information on frequent levels, including the genome, transcriptome (total genes that are converted into transcripts (i.e., mRNA molecules), proteome (whole proteins found in a given cell or tissue), metabolome (whole metabolism products and intermediates in a cell or tissue), interactome (situate of molecules, such as biologically active metabolism products, that interact with a given protein), and phenome (sum of all observable characteristics of an organism) levels. ${ }^{12}$

\section{Different Omic Techniques}

\section{Genomics and its modified techniques}

The study of the human genome along with detection of variability of the DNA is called Genomics. Pharmacogenomics is the study that how pharmaceutical agents interact with the output among the first issues successfully addressed by omics techniques in the herbal research field. ${ }^{22}$ Various assay methods based on DNA polymorphism have been developed for the identification and isolation of herbal products. (Table 1) DNA chips with DNA sequences were soon developed for plant material identification and applied to herbal plants samples. ${ }^{23}$ It proved to be a more powerful tool that could be used for analyzing mixed herbal preparations. Thus, DNA chip technology can recommend a rapid, high-throughput and information-rich tool for genotyping, quality assurance, and species confirmation. Another method development of DNA chip technology was represented by the "DNA barcoding". These methods are used for recognition and identification of herbal samples by comparing sequences of a standard short DNA fragment. These methods are used for identification of unknown species of plants by comparing the DNA barcode sequences from library sequence of known species. This is a more powerful methodology compared to the previous techniques used for identification of herbal samples. ${ }^{24}$

Another techniques related to genomics is Microarray analysis. A mature gene chip methodology allows rapid and detailed assay of thousands of transcripts. When used with this method, the microarray is referred to as transcriptomic technologies. ${ }^{25}$ These method represents one of the most powerful tools for explicates the mechanisms, which are, involves at molecular level and various processes underlying the complex pharma- cological action of herbal formulations. This method when properly used with statistical tools and bioinformatics, it can also be applied to pharmacodynamic, pharmacokinetic and toxicological characterization of herbal drugs. New innovative automatic assays and specific contraption for DNA analysis are day by day emerging, which includes nanoscale DNA sequencing or microsphere-based suspension arrays and mini sequencing. These will no dought give to the next generation of genomic technologies. ${ }^{26}$

\section{Limitations of Genomic}

Pharmacogenomic screening methods are not adopted widely due to their higher cost process. A genomic screen may cost a patient somewhere between $\$ 100$ to more than a few thousand dollars depending upon the number of polymorphisms required, and the vendor pricing. ${ }^{27}$ Single screens have become less expensive with commercialization, consumption of microarray techniques, and increased clinical claim. ${ }^{28}$

\section{Proteomics}

Proteomics is the research area enlightening the temporal dynamics of proteins articulated in a given biological compartment at a given time. ${ }^{29}$ Recently, there has been an modification of the proteomics definition to include not only gene products, but also structural modification of these gene products stirring in cellular metabolisms and turnover (i.e., posttranslational modifications). The identity annotation of human proteins is increasing rapidly; it can be followed on the Internet within public databases. Still, there is a large need for protein function annotations. Bioinformatics tools make predicting putative functions of proteins. ${ }^{30}$ An interesting work has been done in functional proteomic identification of DNA replication proteins by induced proteolysis in vivo. Two-dimensional gel electrophoresis is the most commanding analytical separation technique for proteins. The large-size globular structures of proteins does not allow themselves for chromatographic high-resolution separations due to the unfavorable diffusion coefficients in the separation mechanism. ${ }^{31}$ Techniques are available but a large database of proteomics 'fingerprint' is still wanted for compounds of known toxicity. The products of the genes recognized so far in transcriptomics studies are possibly promising candidates as proteomics markers. ${ }^{32}$

Currently, two approaches based on mass-spectrometry are the most frequently used for global quantitative protein profiling: (1) two-dimensional electrophoresis (2DE) followed by staining, selection, and identification by mass-spectrometry; (2) isotope tags to label proteins, separation by multidimensional liquid chromatography and mass spectrometry analysis. Both basic proteomic approaches can be supplemented with useful information provided by molecular imaging. ${ }^{33}$ In Herba Epimedii in zebra fish combination of proteomic approaches and in vivo imaging

\begin{tabular}{|c|c|c|}
\hline Species & Analytical methods & References \\
\hline Cucumis sativus & De novo genome assembly & Huang et al. $(2009)^{13}$ \\
\hline Fragaria vsca & De novo genome assembly & Shulave et al. $(2011)^{14}$ \\
\hline Jatropa curcas & De novo genome assembly & S.Sato et al. $(2011)^{15}$ \\
\hline Solonum tuberosum & De novo genome assembly & $\mathrm{Xu}$ et al. $(2011)^{16}$ \\
\hline Brassica rapa & De novo genome assembly & Wang et al. $(2011)^{17}$ \\
\hline Oryza sativa & Mapping to reference genome & Yamamoto et al. $(2010)^{18}$ \\
\hline Arabidopsis lyrata & Mapping to reference genome & Turner et al. $(2010)^{19}$ \\
\hline Arabidopsis thaliana & Mapping to reference genome & Cao et al. $(2011)^{20}$ \\
\hline Zea mays & Mapping to reference genome & Lai et al. $(2010)^{21}$ \\
\hline Glycine max & Mapping to reference genome & Lam et al. $(2010)^{22}$ \\
\hline
\end{tabular}


Table 2: Outcomes of Different Plant with proteomics

\begin{tabular}{cccc}
\hline Species & Omic method & Outcome & Reference \\
\hline P. ginseng vs. P. quinquefolium & Proteomics & Identification of species & Zhang et al., 2006 $6^{36}$ \\
Ganoderma & Proteomics & Properties in nerve injury & Zhang et al., 2006 ${ }^{37}$ \\
Salvia miltiorrhiza & Proteomics & Atherosclerotic lesions & Hung et al. 2010 \\
Salvia miltiorrhiza & Proteomics & Cancer & Hung et al. 2010 \\
\hline
\end{tabular}

Table 3: Various Omic methods used in different plant for various activity

\begin{tabular}{|c|c|c|c|}
\hline Species & Omic method & Outcome & Reference \\
\hline $\begin{array}{l}\text { Trypterigium } \\
\text { hypoglaucum }\end{array}$ & cDNA microarray & $\begin{array}{c}\text { Mechnaism of } \\
\text { proapototivc activity }\end{array}$ & Zhuang etal $(2004)^{45}$ \\
\hline Coptidis rizoma & cDNA microarray & $\begin{array}{l}\text { Antiproliferative effect } \\
\text { might be mediated by } \\
\text { interferon }\end{array}$ & Kang et al (2005) ${ }^{46}$ \\
\hline $\begin{array}{l}\text { Radix ginseng, Cornu } \\
\text { cervi pantotrichum }\end{array}$ & cDNA microarray & $\begin{array}{l}\text { Effect of cytokine related } \\
\text { genes on immune } \\
\text { functions }\end{array}$ & Pan-ammarstrom $(2006)^{47}$ \\
\hline $\begin{array}{c}\text { Scutellaria } \\
\text { baicalensis, Coptis } \\
\text { chinensis }\end{array}$ & cDNA microarray & $\begin{array}{c}\text { Using HepG2 cells } \\
\text { indicated that cytotoxic } \\
\text { effect was associated with } \\
\text { change in p53 signalling } \\
\text { pathway }\end{array}$ & Cheng et al (2008) $)^{48}$ \\
\hline $\begin{array}{c}\text { Angelicae } \\
\text { Radix, Pinelliae } \\
\text { tuber,Cinnamoni } \\
\text { Cortex, Ginseng } \\
\text { Radix }\end{array}$ & cDNA microarray & $\begin{array}{c}\text { Identification of } \\
\text { gucocorticoid regulated } \\
\text { kinase involved } \\
\text { in pathogenesis of } \\
\text { Parkinsonism disease. }\end{array}$ & Sakai et al $(2007)^{49}$ \\
\hline $\begin{array}{l}\text { Captidis Rizoma, } \\
\text { Scutellariae Radix, } \\
\text { Phellodendri Cortex } \\
\text { and Gradeniae } \\
\text { Fructus }\end{array}$ & Trancriptonomics & $\begin{array}{c}\text { Adenosine deaminase } \\
\text { may be involved in gastric } \\
\text { ulcers. }\end{array}$ & Watanbe- Fakuda et al (2009) 50 \\
\hline
\end{tabular}

Table 4: Metabolic profiling of various plants with the help of metabolomic

\begin{tabular}{|c|c|c|c|}
\hline Species & Analytical method & Outcome & Reference \\
\hline Scutellaria baicalensis & $\begin{array}{l}\text { Fourier transform ion cyclotron mass } \\
\text { spectrometry }\end{array}$ & $\begin{array}{l}\text { Metabolomic profiling for screening extracts from different } \\
\text { germplasm lines. }\end{array}$ & Murch et al $2004^{54}$ \\
\hline Panax ginseng & NMR spectroscopy-based metabolomics & Used to differentiate Panax ginseng roots of different origins & Kang et al $2008^{55}$ \\
\hline Panax ginseng & UPLC with TOF MS analysis & $\begin{array}{c}\text { Untargeted metabolite profiling and proved reliable for the } \\
\text { rapid analysis of a group of metabolites present in the herbal } \\
\text { extracts }\end{array}$ & Xiang et al $2011^{56}$ \\
\hline Curcuma species & $\begin{array}{l}\text { Hyphenated gas chromatography-mass } \\
\text { spectrometry }\end{array}$ & $\begin{array}{l}\text { used to discriminate and assess the quality of samples of } \\
\text { three Curcuma species from different ecotypes }\end{array}$ & Xiang et al $2011^{57}$ \\
\hline $\begin{array}{l}\text { Gomphrena globosa, } \\
\text { Jasminum sambac }\end{array}$ & UPLC/ESI-SYNAPT ${ }^{\mathrm{mm}}-$ HDMS $^{\mathrm{m}}$ & Efficacy of leaves in myocardial infarction in rats. & Liang et al $2011^{58}$ \\
\hline Rhizoma Drynariae & - & $\begin{array}{l}\text { Therapeutic effect on an experimental rat model of shen yang } \\
\text { deficiency syndrome was investigated by comparing urine } \\
\text { profiles from diseased and treated rats. }\end{array}$ & Su et al $2011^{59}$ \\
\hline
\end{tabular}

has been effectively used for the study of the metabolism of flavonoids. One of the most interesting applications of proteomics in herbal plant research is the ability of these techniques to find different species as in the case of Panax (P. ginseng vs. P. quinquefolium). ${ }^{34}$ Proteomics can prove a valuable tool for quality control, toxicity studies, and standardization of preparations and decoctions. In comparison to genomic and transcriptomic approaches, proteomic assays have been successfully used for describing mechanisms of action of many different herbal preparations. ${ }^{35}$ (Table 2).

Proteomics, now a day's is becoming a valuable tool for elucidating multi-target effects of complex herbal preparations, discovery of single bioactive compounds, development of active fractions, characterization of secure herbal prescriptions and eventually modified molecular diagnosis. ${ }^{39}$ 


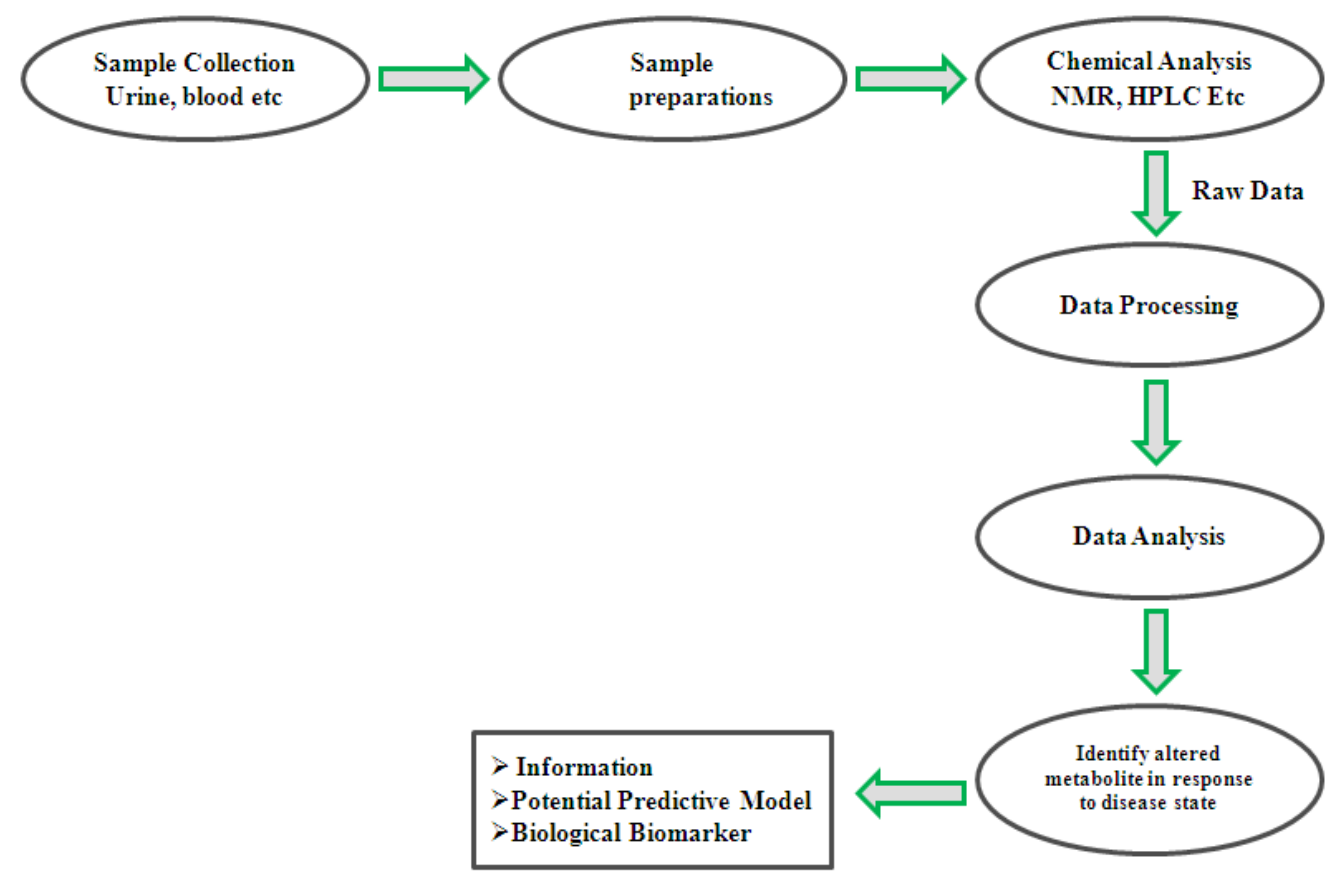

Figure 1: A "typical" and "simplified" workflow for a metabonomic experiment

\section{Limitations of Proteomic}

The major limitation of proteomic is that they are specific to a tissue. Unlike blood-based targets or respected tumor tissue, from which the pertinent biologic matrix is practical to obtain, tissue samples from organs such as lung, kidney, heart, or brain are not easily obtained for proteomic screens. ${ }^{40}$

\section{Transcriptomics}

Transcriptomics is a method that analyzes the expression level of genes by measuring the transcriptome. Transcriptomics make use of high density or high-throughput methods for assessing mRNA expression. ${ }^{41}$ Transcriptomics are actually used as a platform for translational medicine, and DNA microarray technology were used to analyze the biological events induced in different herbal formulae to conclude their therapeutic potential, as well as their safety. By the use of this strategy, it is possible to establish significant similarities with expression signatures. ${ }^{42}$ (Table 3 ).

\section{Microarrays and Qrt-PCR Microarrays}

DNA arrays is the most common approach used for gene expression profiling and are generated by immobilizing a high number of oligonucleotides on an extremely small surface (up to 200,000 spots $/ \mathrm{cm}^{2}$ ). Based on the target sequences, a significant change of mRNA is estimated for thousands of genes. ${ }^{43}$ Specialized sub-sets of gene expression changes and quantitative real-time reverse transcriptase-polymerase chain reactions (qrt-PCR)-based approaches that focus on specific genes have also been developed. The latter is a highly recommended confirmatory tool for quantifying gene expression with improvements in sensitivity and specificity. ${ }^{4}$

\section{Limitations of Transcriptomic}

Transcriptomic analysis had not been successful into the clinical area to date. This field remains established in basic science with few efforts to transfer the technique into translational studies. The fundamental limitation of using transcriptomics assays is that mRNAs are not the main products but they are the intermediate products of disease, which fail to adequately predict the clinical effect. ${ }^{51}$

\section{Metabolomics}

The Systematic study of inimitable chemical fingerprints with definite cellular process is called Metabolomics. This process includes the study of their small-molecule metabolite profiles. The metabolome represents all metabolites collection in a biological organism, which are mainly the products of its gene expression..$^{52}$ The term metabolomics, is mainly framed for exhaustive, nonbiased, high-throughput analyses of complex metabolite mixtures mainly of plant extracts. Chromatographic fingerprinting technique of various herbal plants has proved to be a comprehensive technique for assessing quality of herbal medicines. Metabolomic profiling are used for analysis of extracts by using Fourier transform ion cyclotron mass spectrometry (FTMS). These are mainly examined with the aim of identifying the best phytochemical profiles. ${ }^{54}$ (Table 4 , and Figure 1).

\section{Limitations of Metabolomic}

Further characterization of human metabolom and subsequently therapeutic association can be made for the better results. In addition, this technique raises an issue of reproducibility. It is unclear that how recent clinicians will use this data because even small changes in physiology, such as food intake or going up a flight of stairs can have significant impact on the metabolome. Combination of pharmacometabolomics with pharmacogenomics can lead to screening of more clinically relevant data.

\section{CONCLUSION}

Omics techniques were developed in response to the need for correct information at physiological as well as at genetic level of herbal plants. The different omic techniques are now a day's used all over world for standardization and quality control of herbal formulae, mechanism of action, characterization, identification of molecular mechanism for prediction of side effects and interaction with other drugs.

Although thereis, manyadvantages of omictechniquesbut theirappliance are restricted in thefield of herbaldrugstandardization and quantification. The result obtained with the use the omic techniques are accomplished 
but additional work need to be undertaken to concern their full prospective. All the omic process is gradually but firmly approaching their way in herbal standardization. In all the techniques of omics, metabonomics seem to be hastily gaining ground with respect to the other techniques. This is possibly due to minimalism of their experimental design, which allows direct and meticulous analysis of large number of biological sample.

\section{ACKNOWLEDGEMENT}

Author are thankful to Chhattisgarh council of science and technology (F. No.:- 1922/CCOST MRP 2012-13) for there financial support.

\section{CONFLICT OF INTEREST}

The author declare no conflict of interest.

\section{ABBREVIATIONS USED}

WHO: World Health organization, DNA: Deoxyribose Nucleic acid, RNA: Ribose Nucleic acid, PCR: Polymerase chain reaction, mRNA: Messenger Ribose Nucleic acid, 2DE: Two-dimensional electrophoresis, FTMS: Fourier transforms ion cyclotron mass spectrometry.

\section{ABOUT AUTHOR}

Dr. Ravindra Pandey: Is Associate Professor in the Department of Pharmacognosy and has completed his Ph.D. from University Institute of Pharmacy, Pt. Ravi Shanakar Shukla University, Raipur (C.G.)

\section{REFERENCES}

1. Barreto FS, Sousa EO, Campos AR1, Costa JGM, Rodrigues FFG. Antibacterial Activity of Lantana camara Linn and Lantana montevidensis Brig Extracts from Cariri-Ceara, Brazil. J Young Pharm. 2010;2(1):42-4

2. Drug interactions between herbal and prescription medicines. Drug Safety. 2003;26(15):1075-92.

3. Shukla SS, Saraf S, Saraf S. Approaches towards Standardization and Quality Assessment of Herbals. J Res Educ Indian Med. 2009;15(1):25-32.

4. Pandey R, Shukla SS, Saraf Sw, Saraf Sh, Journa of Planar Chromatography. 2013:26(5):440-4

5. Holmes C, McDonald F, Jones M, Ozdemir V, Janice E. Graham. Standardization and Omics Science: Technical and Social Dimensions Are Inseparable and Demand Symmetrical Study. OMICS A J of Inte Bio. 2010;14(3):3-10.

6. Jackson O, Lay Jr, Borgmann S, Liyanage R, Wilkins CL. Problems with the "omics'. Trends in Analytical Chemistry. 2006;25(11):11-5.

7. Dobos T. The model of Western integrative medicine: the role of Chinese medicine. Chi. J of Int Med. 2011:17:11-20.

8. Gowda N, Zhang S, Haiwei G, Asiago V, Shanaiah N, Raftery D. MetabolomicsBased Method for Early Disease Diagnostics: A Review. Expert Rev Mol Diagn. 2008;8(5):617-33

9. Wang L, McLeod HL, Weinshilboum RM. Genomics and drug response. N Eng J Med. 2011;364(12):1144-53.

10. Burian A. Omic techniques in systems biology approaches to traditiona Chinese medicine research: Present and future. J of Ethn. 2012;140(3):535-44.

11. Trevino V, Falciani F, Hugo ABS. DNA Microarrays: a Powerful Genomic Tool for Bio medical and Clinical Research. Mol Med. 2007;13(9):527-41.

12. Ulrich MG, Zeitler $H$, Jobst $D$, Panek $D$, Vetter $H$, Wagner $H$. Application of the 'Omic' technologies in phytomedicine. Phyto. 2007;14(1):70-82.

13. Chavan $P$, Joshi $K$, Patwardhan B. DNA microarrays in herbal drug research eCAM. 2006;3(4):447-57.

14. Fischer HP. Mathematical Modeling of Complex Biological Systems. Alco Res and Health. 2008:31(1):49-59.

15. Huang S, Li R, Zhang Z, Li L, Gu X, Fan W. The genome of the cucumber, Cucumis sativus L. Nat Genet. 2009;41(12):1275-81.

16. Shulaev V, Sargent DJ, Crowhurst RN, Mockler TC, Folkerts O, Delcher AL. The genome of woodland strawberry (Fragaria vesca). Nat. Genet. 2011;43(2):109-16.

17. Saito T, Ariizumi T, Okabe $Y$, Asamizu E, Hiwasa TK, Fukuda N. TOMATOMA a novel tomato mutant database distributing Micro-Tom mutant collections. Plant Cell Physiol. 2011:52:283-96.

18. Xu X, Pan S, Cheng S, Zhang B, Mu D, Ni P. Genome sequence and analysis of the tuber crop potato. Nature. 2011;475:189-95.

19. Wang $X$, Wang $H$, Wang J, Sun R, Wu J, Liu S. The genome of the mesopolyploid crop species Brassica rapa. Nat Genet. 2011;43:1035-9.

20. Yamamoto T, Nagasaki H, Yonemaru J, Ebana K, Nakajima M, Shibaya T. Fine definition of the pedigree haplotypes of closely related rice cultivars by means of genome-wide discovery of single-nucleotide polymorphisms. BMC Genomics. 2011:11(1):267-71.

21. Turner TL, Bourne EC, Von W EJ, Hu TT, Nuzhdin, SV. Population resequencing reveals local adaptation of Arabidopsis lyrata to serpentine soils. Nat Genet. 2010;42(3):260-3
22. Cao J, Schneeberger K, Ossowski S, Gunther, Bender S, Fitz J. Wholegenome sequencing of multiple Arabidopsis thaliana populations. Nat Genet. $2011 ; 43(10): 956-63$

23. Lai J, Li R, Xu X, Jin W, Xu M, Zhao H. Genome-wide patterns of genetic variation among elite maize inbred lines. Nat Genet. 2010;42(11):1027-30.

24. Lam HM, Xu X, Liu X, Chen W, Yang G, Wong FL. Resequencing of 31 wild and cultivated soybean genomes identifies patterns of genetic diversity and selection. Nat Genet. 2010;42(12):1053-9.

25. Evans DA, Manley KA, McKusick VA. Genetic control of isoniazid metabolism in man. Br Med J. 1960; 2:485-491.

26. Crettol S, Petrovic N, Murray M. Pharmacogenetics of phase I and phase II drug metabolism. Curr Pharm Des. 2010;16(2):204-19.

27. Debashis G, Zhaohui SQ. Statistical Issues in the Analysis of ChIP-Seq and RNA-Seq Data. Genes. 2010:1(2):317-34.

28. Lobello KW, Preskorn SH, Guico-Pabia CJ, Jiang Q, Paul J. Cytochrome P450 2D6 phenotype predicts antidepressant efficacy of venlafaxine: a secondary analysis of 4 studies in major depressive disorder. J Clin Psychiatry. 2010; 71(11):1482-7.

29. Epstein RS, Moyer TP, Aubert RE, Kane DJ, Xia F. Warfarin genotyping reduces hospitalization rates results from the MM-WES (Medco-Mayo Warfarin Effectiveness study). J Am Coll Cardiol. 2010;55(25):2804-12

30. CaracoY, Blotnick S, Muszkat M. CYP2C9 genotype-guided warfarin prescribing enhances the efficacy and safety of anticoagulation: a prospective randomized controlled study. Clin Pharmacol Ther. 2008;83(3):460-70.

31. Calvel P, Antoine DR, Bernard J, Charles P. Testicular postgenomics: targeting the regulation of spermatogenesis. Phil Trans R Soc B. 2010;365(1546):1481-500.

32. Altelaar AM, Heck AJ. Trends in ultrasensitive proteomics. Curr Opin Chem Biol. 2012;(2):205-10

33. Mateos CPJ, Macaya C, Azcona L, Modrego J, Mahillo E. Different expression of proteins in platelets from aspirin-resistant and aspirin-sensitive patients. Thromb Haemost. 2010;103(1):160-70.

34. Mark RF, Timothy JG, Daniel M, Ruedi A. Advances in quantitative proteomics using stable isotope tags. Tre in Biotech. 2002;20(12):12-8.

35. Li ZH, Alex D, Siu SO, Chu IK, Renn J, Winkler C. Combined in vivo imaging, and omics approaches reveal metabolism of icaritin and its glycosides in zebrafish larvae. Mole Biosyste. 2011;7(7):2128-38.

36. Lum JH, Fung KL, Cheung PY, Wong MS, Lee CH, Kwok FS. Proteome of oriental Panax ginseng and the potential to use it as an identification tool Proteomics. J Clin Invest. 2002;2(9):1123-30.

37. Zhang W, Zeng YS, Wang Y, Liu W, Cheng JJ, Chen SJ. Primary study on proteomics about Ganoderma lucidium spores promoting survival and axon regeneration of injured spinal motor neurons in rats. Chem Biol. 2006:4(3):298-302.

38. Hung YC, Wang PW, Pan TL. Functional proteomics reveal the effect of Salvia miltiorrhiza aqueous extract against vascular atherosclerotic lesions. Biochimica et Biophysica Acta. 2010;1804(6):1310-21.

39. Cho WCS. Application of proteonomics in Chinese medicine research. Am J of Chinese med. 2007:35(6):911-22.

40. Andrew AM, Vasilis V, Kennon JH. Omics Screening for Pharmaceutical Efficacy and Safety in Clinical Practice. J Pharmacogenomics Pharmacoproteomics. 2012:S5:1-19. 
41. Powell EE, Kroon PA. Low density lipoprotein receptor and 3-hydroxy-3-methylglutaryl coenzyme, A reductase gene expression in human mononuclear leukocytes is regulated coordinately and parallels gene expression in human liver. $J$ Clin Invest. 1994;93(5):2168-74.

42. Brien O, Abboud S, Akhtari C, Altman M, Berman JE. NCCN Guidelines TM. National Comprehensive Cancer Network. 2012.

43. Hala MA. New Trends in Genotoxicity Testing of Herbal Medicinal Plants. Chapter 1.89-120.

44. Wilson VS, Keshava N, Hester S, Segal D, Chiu W, Thompson CM, Euling SY. Utilizing toxicogenomic data to understand chemical mechanism of action in risk assessment. Toxi and App Pharmaco. 2011; in press.

45. Zhuang WJ, Fong $\mathrm{CC}$, Cao J, Ao L, Leung $\mathrm{CH}$, Cheung $\mathrm{HY}$, et al. Involvement of NF-B and c-myc signaling pathways in the apoptosis of HL-60 cells induced by alkaloids of Tripterygium hypoglaucum (levl.) Phytomed. 2004;11(4):295-302

46. Kang J, Lee S, Kang S, Kwon HN, Park JH, Kwon SW et al. NMR-based metabolomics approach for the differentiation of ginseng (Panax ginseng) roots from different origins. Arch of Pharmacal Res. 2008;31(3):330-6.

47. Hammarstrom P, Wen Q, Hammarstrom SL. Cytokine gene expression profiles in human lymphocytes induced by a formula of traditional Chinese medicine, vigconic VI-28. J of Interferon and Cytokine Res. 2006;26(9):628-36.

48. Cheng WY, Wu SL, Hsiang CY, Li CC, Lai TY, Lo HY, et al. Relationship between San-Huang-Xie-Xin- Tang and its herbal components on the gene expression profiles in HepG2 cells. Ame J of Chinese Med. 2008;36(4):783-97.

49. Sakai R, Irie Y, Murata T, Ishige A, Anjiki N, Watanabe K. Toki-to protects dopaminergic neurons in the substantia nigra from neurotoxicity of MPTP in mice. Phytotherapy Res. 2007;21(9):868-73.

50. Watanabe FY, Yamamoto M, Miura N, Fukutake M, Ishige A, Yamaguchi R.
Berberine improve indomethacin-induced small intestinal injury via adenosine. $\mathrm{J}$ of Gastroenterology. 2009;44(5);380-9.

51. Mendrick DL. Transcriptional profiling to identify biomarkers of disease and drug response. Pharmacogenomics. 2011;12(12):235-49.

52. Johnson $\mathrm{CH}$, Patterson AD, Idle JR, Gonzalez FJ. Xenobiotic metabolomics: major impact on the metabolome. Annu Rev Pharmacol Toxicol. 2012;52:37-56.

53. Zhang $A$, Sun $H$, Wang $P$, Han $Y$, Wang $X$. Modern analytical techniques in metabolomics analysis. Analyst. 2012;137(2):293-300.

54. Murch SJ, Rupasinghe HP, Goodenowe D, Saxena PK. A metabolomic analysis of medicinal diversity in Huang-qin (Scutellaria baicalensis Georgi) genotypes: discovery of novel compounds. Plant Cell Reports. 2004;23(6):419-25.

55. Kang J, Lee S, Kang S, Kwon HN, Park JH, Kwon SW. Park NMR-based metabolomics approach for the differentiation of ginseng (Panax ginseng) roots from different origins. Archives of Pharmacal Research. 2008;31(3):330-6.

56. Xie G, Plumb R, Su M, Xu Z, Zhao A, Qiu M. Ultra-performance LC/TOF MS analysis of medicinal Panax herbs for metabolomic research. J of Sepa Scie. 2008;31(6-7):1015-26.

57. Xiang Z, Wang XQ, Cai XJ, Zeng S. Metabolomics study on quality control and discrimination of three curcuma species based on gas chromatograph-mass spectrometry. Phytochemical Analysis. 2011;22(5):411-8.

58. Liang $X$, Chen $X$, Liang $Q$, Zhang H, Hu P, Wang Y. Metabonomic study of Chinese medicine Shuanglong formula as an effective treatment for myocardial infarction in rats. J of Proteome Res. 2011;10:790-9.

59. Su ZH, Li SQ, Zou GA, Yu CY, Sun YG, Zhang HW. Urinary metabonomics study of anti-depressive effect of Chaihu-Shu-Gan-San on an experimental model of depression induced by chronic variable stress in rats. J of Pharma and Biomed Analy. 2011;55(3):533-9. 